\title{
A study of visual inspection of cervix under acetic acid and visual inspection of cervix under Lugol's iodine for screening of carcinoma cervix
}

\author{
Sunita Kanash ${ }^{1}$, S. D. Shirodkar ${ }^{1}$, Swati Gawai ${ }^{2 *}$ \\ ${ }^{1}$ Department of Obstetrics and Gynecology, TNMC and BYL Nair Hospital Mumbai, Maharashtra, India \\ ${ }^{2}$ Department of Obstetrics and Gynecology, LTMMC and Sion Hospital Mumbai, Maharashtra, India
}

Received: 30 April 2019

Revised: 09 August 2019

Accepted: 12 August 2019

\section{*Correspondence:}

Dr. Swati Gawai,

E-mail: gawai.swati@gmail.com

Copyright: $\odot$ the author(s), publisher and licensee Medip Academy. This is an open-access article distributed under the terms of the Creative Commons Attribution Non-Commercial License, which permits unrestricted non-commercial use, distribution, and reproduction in any medium, provided the original work is properly cited.

\section{ABSTRACT}

Background: Carcinoma cervix is the most common cancer among women in developing countries. The objectives of the study were to study the sensitivity and specificity of visual inspection of the cervix with acetic acid (VIA) and Lugol's iodine (VILI) for cervical cancer screening. To study the correlation of demographic data like age, socioeconomic status, education residential area, parity, age at marriage in premalignant lesion of the cervix.

Methods: The present study was conducted in the department of Obstetrics and Gynecology at a Tertiary Medical Care Center over a period of two years. Five hundred fifty women between 20-65 years of age who fulfilled the selection criteria were enrolled in our study. Positive tests for VIA was opaque aceto white lesion on applying 5\% acetic acid or detection of definite yellow iodine non uptake areas with Lugol's iodine in the transformation zone or close to touching the squamocolumnar junction. Positive cases were scheduled for cervical biopsy. Ethical approval of the study protocol was obtained from the ethics committee of the institute.

Results: On down staging 7.2\% (40/550) of cases had an unhealthy cervix and $0.36 \%(2 / 550)$ with a suspicious cervix. VIA positive in $4.55 \%$ (25/550), VILI positive in $2.73 \%$ (15/550). Biopsy was taken from positive with VIA and VILI. On histology $2.9 \%$ (16) were chronic cervicitis, CIN I had (1), $0.2 \%$, CIN II (2) $0.4 \%$, CIN III (4) $0.7 \%$ and squamous cell carcinoma (2) $0.4 \%$ VIA sensitivity $72.22 \%$, specificity $97.74 \%$. VILI sensitivity $100 \%$, specificity 98.89\%.

Conclusions: VIA and VILI are simple, inexpensive, low resources technique. Both have high sensitivity and specificity.

Keywords: Cervical intraepithelial lesion, Screening of carcinoma cervix, VIA, Visual inspection of cervix under acetic acid, Visual inspection of cervix under Lugol's iodine, VILI

\section{INTRODUCTION}

Worldwide, approximately 500,000 new cases of cervical cancer (approximately 1 case per minute) are diagnosed, and 2,75,000 related deaths occur annually, making it the second or third most common female cancer and subsequent mortality. It is the cause of about one tenth of all female cancer deaths. ${ }^{1}$

Carcinoma cervix is the most common cancer among women in developing countries. ${ }^{2}$ In India, an estimated 1.5 lakh women develop cervical cancer annually, about 
16 percent of the world annual incidence. Thus, cervical cancer is an important public health problem that deserves urgent attention. ${ }^{3}$

Well established screening programs for early detection of carcinoma cervix are present in developed countries, which is contrary to the scenario in developing countries like India where there is lack of infrastructure, trained health personnel and financial constraints.

\section{METHODS}

The present study was conducted in the Obstetrics and Gynecology department at a Tertiary Medical Care Center over a period of two years. Five hundred fifty women between 20-65 years of age who fulfilled the selection criteria were enrolled in our study.

Positive tests for VIA was opaque aceto white lesion on applying 5\% acetic acid or detection of definite yellow iodine non uptake areas with Lugol's iodine in the transformation zone or close to touching the squamocolumnar junction. Positive cases were scheduled for cervical biopsy.

\section{Inclusion criteria}

- All women aged between 20 to 65 .

\section{Exclusion criteria}

- Known case of carcinoma cervix.

- The pregnancy

\section{Preparation of 5\% acetic acid}

\section{Ingredients}

- $100 \%$ glacial acetic acid: $5 \mathrm{ml}$

- Distilled water: $95 \mathrm{ml}$

\section{Preparation:}

- Carefully add $5 \mathrm{ml}$ of glacial acetic acid into $95 \mathrm{ml}$ of distilled water and mix thoroughly.

Storage: Unused acetic acid should be discarded at the end of the day.

Label: $5 \%$ dilute acetic acid.

\section{Preparation of Lugols's iodine}

\section{Ingredients}

- Potassium iodide: $10 \mathrm{~g}$

- Distilled water: $100 \mathrm{ml}$

- Iodine crystals: $5 \mathrm{~g}$

\section{Preparation}

- Dissolve $10 \mathrm{~g}$ potassium iodide in $100 \mathrm{ml}$ of distilled water

- Slowly add 5g iodine crystals, while shaking

- Filter and store in a tightly stopper brown bottle.

Storage: 1 month.

Label: Lugol's iodine solution; Use by date.

\section{Procedure}

Written and informed consent was obtained from all the participants and the procedure was explained. The woman was asked to void urine and placed in dorsal position. Under all aseptic precautions, Cusco's speculum was inserted. The cervix was visualized for any gross pathological features under adequate and results were concluded according to WHO guidelines. In patients with the lax vaginal wall, examination of the cervix was done using a large Sim's speculum and anterior vaginal wall retractor. All findings were carefully recorded in the proforma.

Pap smear was taken from all patients. After cleaning the cervix with normal saline, freshly prepared $5 \%$ acetic acid was taken with a swab stick and generously applied on the cervix. The cervix was inspected after one minute. After results of VIA, cervix was cleaned with normal saline and Lugol's iodine was generously applied to the cervix and was inspected under good light source.

A biopsy was taken from VIA and/or VILI positive area or suspicious looking cervical area using punch biopsy forceps. The specimen was sent to histopathology labin formalin solution. Slides were analyzed by experienced consultant pathologist.

Biopsyresults were categorized as normal, chronic cervicitis, mild dysplasia (CIN 1), moderate dysplasia (CIN 2), severe dysplasia (CIN3), carcinoma in situ (CIN3), invasive carcinoma.Keeping biopsy as the gold standard, sensitivity and specificity of down staging were noted. Similarly, sensitivity and specificity of VIA and VILI were computed.

\section{RESULTS}

550 patients were down staged and out of 550 patients 40 found to have abnormal cervix while 2 were suspicious of malignancy.

Table 1: Down staging of patients.

\begin{tabular}{|llll|} 
Total & $\begin{array}{l}\text { Normal } \\
\text { cervix }\end{array}$ & $\begin{array}{l}\text { Abnormal cervix } \\
\text { (unhealthy) }\end{array}$ & $\begin{array}{l}\text { Suspicious } \\
\text { cervix }\end{array}$ \\
\hline 550 & 508 & 40 & 2 \\
\hline
\end{tabular}


In the present study maximum women $174(31.6 \%)$ belong to the group 31 to 40 years. Increasing age was associated with increased grades of dysplasia. In present set up most women of age group, 31-40 years were symptomatic and therefore comprised the bulk of cases. Peak reproductive years are associated with infection and consequent dysplasia.

Table 2: Distribution as per age group $(\mathrm{N}=550)$.

\begin{tabular}{|c|c|c|}
\hline Age & Frequency & Percent \\
\hline 20 to 30 years & 164 & 29.8 \\
\hline 31 to 40 years & 174 & 31.6 \\
\hline 41 to 50 years & 139 & 25.3 \\
\hline 51 to 60 years & 50 & 9.1 \\
\hline 60 to 65 years & 23 & 4.2 \\
\hline Total & 550 & 100.0 \\
\hline
\end{tabular}

Table 3: Distribution as per socio economic status.

\begin{tabular}{|lll|}
\hline SES & Frequency & Percent \\
\hline High & 48 & 8.7 \\
\hline Middle & 265 & 48.2 \\
\hline Low & 237 & 43.1 \\
\hline Total & $\mathbf{5 5 0}$ & $\mathbf{1 0 0 . 0}$ \\
\hline
\end{tabular}

$48.2 \%$ of cases belonged to middle socioeconomic status. Lowsocio economic status patients are $43.1 \%$ were associated with poor hygiene, higher infection rate, lack of awareness. Thus, out of 550 patients maximum were of middle and low socioeconomic status.

Table 4: Distribution as per age at marriage age.

\begin{tabular}{|lll|}
\hline Age at marriage & Frequency & Percent \\
\hline less than 15 years & 3 & 0.5 \\
\hline 15 to 20 years & 315 & 57.3 \\
\hline 21 to 25 years & 229 & 41.6 \\
\hline More than 25 years & 3 & 0.5 \\
\hline Total & $\mathbf{5 5 0}$ & $\mathbf{1 0 0 . 0}$ \\
\hline
\end{tabular}

It was seen maximum with age group between 15-25 years age of marriage by law is after 18 years of age, but in present study maximum patients got married before age of 18 years. $57.3 \%$ got married between $15-20$ years of age.

Table 5: Distribution as per geographical location.

\begin{tabular}{|lll|}
\hline Location & Frequency & Percent \\
\hline Urban & 252 & $45.8 \%$ \\
\hline Rural & 298 & $54.2 \%$ \\
\hline Total & $\mathbf{5 5 0}$ & $\mathbf{1 0 0 . 0}$ \\
\hline
\end{tabular}

Inspite of the presence of four major hospitals in nearby area we got an almost equal distribution of patients from rural and urban area, that is $45.8 \%$ of cases belonged to an urban area and 298 (54.2\%) of cases belonged to rural areas.

Parity is one of the important risk factors. Multiparous patients are more prone to develop cancer cervix. In the present, one nulligravida cases had invasive carcinoma. The majority of the study group were Para 2 and para 3 $(62.2 \%) 342$. Grand multiparous only 31 patients.

Table 6: Distribution of cases as per parity $(n=550)$.

\begin{tabular}{|lll|}
\hline Ob History & Frequency & Percent \\
\hline Nulliparous & 13 & 2.4 \\
\hline Para 1 & 116 & 21.1 \\
\hline Para 2 & 203 & 36.9 \\
\hline Para 3 & 139 & 25.3 \\
\hline Para 4 & 48 & 8.7 \\
\hline Para 5 and above & 31 & 5.6 \\
\hline Total & $\mathbf{5 5 0}$ & $\mathbf{1 0 0 . 0}$ \\
\hline
\end{tabular}

VIA and VILI was performed in all women who fulfilled the inclusion criteria.

Table 7: Results of via $(n=550)$.

\begin{tabular}{|lll|}
\hline VIA & Frequency & Percent \\
\hline Positive & 25 & 4.5 \\
\hline Negative & 525 & 95.5 \\
\hline Total & $\mathbf{5 5 0}$ & $\mathbf{1 0 0 . 0}$ \\
\hline
\end{tabular}

Table 8: Results of VILI $(n=550)$.

\begin{tabular}{|lll|}
\hline VILI & Frequency & Percent \\
\hline Positive & 15 & 2.7 \\
\hline Negative & 535 & 97.3 \\
\hline Total & $\mathbf{5 5 0}$ & $\mathbf{1 0 0 . 0}$ \\
\hline
\end{tabular}

Cervix becomes well defined aceto white areas after the application of acetic acid that is VIA positive. Twentyfive $(4.5 \%)$ women out of five hundred fifty had a positive result and five hundred fifty $(95.5 \%)$ women had a negative result on VIA.

Table 9: Results of VIA and VILI Positive $(n=550)$.

\begin{tabular}{|llll|}
\hline Test & Positive no. & Percentage & Total \\
\hline Only VIA & 25 & $4.5 \%$ & 550 \\
\hline VILI + VIA & 15 & $2.7 \%$ & 550 \\
\hline
\end{tabular}

The sensitivity of VIA in the present study is $72.22 \%$ and Specificity is $97.74 \%$, positive predictive value (PPV) is $52.00 \%$, negative predictive value (NPV) is $99.05 \%$, the percentage of false negative is $27.7 \%$, the percentage of false positive is $2.26 \%$, accuracy is $96.90 \%$.

VILI positive if dense, thick, bright, mustard-yellow or saffron-yellow iodine non-uptake areas are seen in the transformation zone. Fifteen $(2.7 \%)$ women out of five 
hundred fifty had positive result and five hundred thirtyfive $(97.3 \%)$ women had a negative result on VILI.

The sensitivity of VILI in the present study is $100 \%$ and specificity is $98.89 \%$, positive predictive value (PPV) of VILI is $60 \%$, negative predictive value (NPV) is $100 \%$, the percentage of false positive is $1.10 \%$, accuracy is $98.90 \%$.

15 out of 550 were both VIA and VILI positive. 25 were only VIA positive. A biopsy was taken from positive patients. This test detected seven cases with precancerous lesions, which included $1(0.2 \%)$ case of CIN1, $2(0.4 \%)$ cases of CIN2 and $4(0.7 \%)$ cases of CIN 3, $2(0.4 \%)$ cases of squamous cell carcinoma detected. Among 25 cases, $16(2.9 \%)$ were chronic cervicitis.

Table 10: Distribution of cases as per histopathology $(n=25)$.

\begin{tabular}{|lll|}
\hline Histopathology & Frequency & Percent \\
\hline Chronic cervicitis & 16 & 2.9 \\
\hline CIN I & 1 & 0.2 \\
\hline CIN II & 2 & 0.4 \\
\hline CIN III & 4 & 0.7 \\
\hline Squamous cell carcinoma & 2 & 0.4 \\
\hline Total & $\mathbf{5 5 0}$ & $\mathbf{1 0 0 . 0}$ \\
\hline
\end{tabular}

Out 550 of which twenty-five were VIA positive; fifteen were VIA and VILI both positive; ten were only VILI positive. All the positive patients had undergone biopsy, report of which suggested as-Chronic cervicitis were sixteen, CIN I were one, CIN II were two, CIN III-four, Invasive carcinoma-two.

The remaining seventeen patients having negative VIA and VILI with unhealthy cervix also undergone cervical biopsy. The report suggested, five as normal, two with acute cervicitis, and ten with chronic cervicitis.

\section{DISCUSSION}

The cervical cancer is a potentially preventable cancer. ${ }^{4}$ It is preceded by premalignant lesions which may take 5-15 yrs to progress to invasive cancer. ${ }^{4}$ If detected and treated timely, the pre-invasive disease has nearly 100 percent cure rate with the simple surgical procedure, while advanced cancers have less than 35 percent survival rates. ${ }^{4}$ However, in developing countries like India, universal screening has not been achieved. The main screening method (Pap smear) is available to a small percentage of the population. Cytology-based screening programs are difficult to organize owing to limited infrastructure, trained personnel and funds. ${ }^{5}$

It has been estimated that in India, even with a major effort to expand cytology services, it will not be possible to screen even one-fourth of the population once in a lifetime. ${ }^{6}$ Moreover, screening programs in India are mostly institution based and are restricted to urban centers. ${ }^{7}$ Thus, in developing countries, there is a need for alternative strategies for early detection of premalignant cervical lesions. ${ }^{7}$ Pap smear has various limitations besides low sensitivity. ${ }^{8,9}$ These include the need for repeated visits for screening, a collection of the report, evaluation of abnormal results and treatment, and the requirement for laboratory infrastructure, highly trained cytopathologists and staff for large-scale screening. This hinders the use of Pap smear on a large scale in lowresource settings. This has led to the need for alternate methods which are cheap, easy to perform, can be done by paramedical workers and give immediate results

VIA is more sensitive than conventional cytology in detecting intraepithelial lesions, though it has a lower specificity.

The sensitivity and specificity of VIA in the present study were comparable to that of other studies. The large variation in these results indicates that several variables affect the test characteristics of visual inspection with acetic acid. These are observer training, criteria for test positivity, inter-observer variation, presence of coexisting infection, inflammation, and metaplasia.

Iodine negative areas include columnar epithelium (lacking glycogen), patchy uptake peripheral areas due to cervicitis, and immature metaplasia. These can be mistaken by inexperienced workers as VILI positive. Mustard yellow areas with distinct borders suggest more severe disease. The colour changes with VILI are more easy to appreciate than the changes after VIA.

Advantages of VILI are that it is easily available, can be easily performed by paramedical workers and doctors, test results are immediately available and hence "see and treat" policy can be used, low cost, need not be freshly prepared (as compared to acetic acid), and longer shelf life (1 month) as compared to acetic acid. In the present study, results of VILI positive CIN1 and CIN2 cases corroborated well with other studies, while the percentage of VILI positive cases which turned out to be benign on histopathology was lower. This low test positivity could be due to the fact that only mustard yellow areas were taken as VILI positive, and partial iodine uptake was considered as VILI negative. ${ }^{8,9}$

\section{CONCLUSION}

A woman negative by VIA/VILI need not further undergo any investigation. However, these women are advised follow-up after a minimum interval of 6 months. Only 10-15 percent women who tested positive with the visual techniques required further evaluation.

The results of the present study indicate that VIA and VILI could be used as screening modalities in lowresource settings because they are simple and 
inexpensive. So this technique can be carried out worldwide and easily at every health care centers.

In our study Pap smear was taken of every patient before doing VIA and VILI though it was not the part of the present study. Pap smear is itself a screening procedure. Co -test (HPV + cytology) and colposcopy gives better result but could not be done due to lack of colposcope. All the patients having cervicitis were treated symptomatically.

Patients with CIN were followed up every six months. Eighteen patients had undergone hysterectomy. Two patients were reported as invasive carcinomas on biopsy; out of which one patient was being defaulter and reported late when the case was inoperable and received (RT): radiotherapy; the other one had undergone Wertheim's hysterectomy and then radiotherapy.

But the scenario is not the same in developing countries due to lack of infrastructure, trained health personnel, and financial constraints. Hence, there is a need to implement low-cost strategies like visual inspection with acetic acid and visual inspection with lugol's iodine as compared to cytology. The simple and very cheap method is a visual inspection of the cervix after application of acetic acid.

The present study was carried out to detect the sensitivity and specificity of visual inspection with acetic acid (VIA) and visual inspection with Lugol's iodine (VILI) with cervical biopsy as the gold standard.

Funding: No funding sources Conflict of interest: None declared

Ethical approval: The study was approved by the Institutional Ethics Committee

\section{REFERENCES}

1. Mahmmoobehs, Diane S, Philip EC. Cervical cancer prevention. Cervical screening, science in evolution. Obstet Gynecol Clin N Am. 2007;(34):739-60.
2. Sankarnarayan R, Esmy PO, Rajkumar R, Muwonge $\mathrm{R}$, Swaminathan R, Shanthakumari S. Effect of visual screening on cervical incidence and mortalityin Tamil Nadu: a cluster-randomized trial. Lancet. 2007;4370(9585):398-406.

3. Sehgal A. Human Papilloma virus (HPV) and screening strategies forcervical cancer. Indian J Med Res. 2009; 130:234-40.

4. Dinshaw KA, Shastri SS. Screening for cervical cancer in 3, India. Natl Med J India. 2001;14:1-3.

5. Shastri SS, Dinshaw K, Amin G, Goswami S, Patil S, Chinoy R, et al. Concurrent evaluation of visual, cytological and HPV testing as screening methods for early detection of cervical neoplasia in Mumbai, India. Bull World Health Organ. 2005;83:186-94.

6. Juneja A, Sehgal A, Sharma S, Pandey A. Cervical cancer 5. Screening in India: Strategies revisited. Indian J Med Sci. 2007;61:34-47.

7. Misra JS, Gupta HP, Das V. Assessing the feasibility of single 6. Lifetime PAP smear evaluation between 41-50 years of age as strategy for cervical cancer control in developing countries from our 32 years of experience of hospital-based routine cytological screening. Diagn Cytopathol. 2004;31:376-9.

8. Sankaranarayanan R, Chatterji R, Shastri SS, Wesley RS, Basu P, Mahe C, et al. Accuracy of human papillomavirus testing in primary screening of cervical neoplasia: Results from a multicentre study in India. Int J Cancer. 2004;112:341-7.

9. Goel A, Gandhi G, Batra S, Bhambhani S, Zutshi V, Sachdeva P. Visual inspection of the cervix with acetic acid for cervical intraepithelial lesions. Int $\mathbf{J}$ Gynaecol Obstet. 2005;88:25-30.

Cite this article as: Kanash S, Shirodkar SD, Gawai S. A study of visual inspection of cervix under acetic acid and visual inspection of cervix under Lugol's iodine for screening of carcinoma cervix. Int J Reprod Contracept Obstet Gynecol 2019;8:3505-9. 